\title{
Chronic treatment of JTP-109192, a novel G-protein coupled receptor 119 agonist, improves metabolic abnormalities in Zucker Fatty rats
}

\section{AUTHOR(S):}

Tadaki, Hironobu; Sasase, Tomohiko; Fukuda, Sumiaki; Toriniwa, Yasufumi; Harada, Kazuhito; Ohta, Takeshi; Yamada, Takahisa

\section{CITATION:}

Tadaki, Hironobu ... [et al]. Chronic treatment of JTP-109192, a novel G-protein coupled receptor 119 agonist, improves metabolic abnormalities in Zucker Fatty rats. Clinical and Experimental Pharmacology and Physiology 2019, 46(10): 910-919

\section{ISSUE DATE:}

2019-10

\section{URL:}

http://hdl.handle.net/2433/245455

\section{RIGHT:}

This is the peer reviewed version of the following article: Tadaki, H, Sasase, T, Fukuda, S, et al. Chronic treatment of JTP - 109192, a novel G - protein coupled receptor 119 agonist, improves metabolic abnormalities in Zucker Fatty rats. Clin Exp Pharmacol Physiol. 2019; 46: 910 - 919, which has been published in final form at

https://doi.org/10.1111/1440-1681.13152. This article may be used for non-commercial purposes in accordance with Wiley Terms and Conditions for Use of Self-Archived Versions.; The full-text file will be made open to the public on 30 August 2020 in accordance with publisher's 'Terms and Conditions for Self-Archiving'.; This is not the published version. Please cite only the published version.; この論文は出版社版でありません。引用の際には出版社版をご確認ご利用くだ 


\section{Title}

Chronic treatment of JTP-109192, a novel G-protein coupled receptor 119 agonist, improves metabolic abnormalities in Zucker Fatty rats

\section{Authors}

Hironobu Tadaki ${ }^{1}$, Tomohiko Sasase ${ }^{1}$, Sumiaki Fukuda ${ }^{1}$, Yasufumi Toriniwa ${ }^{1}$, Kazuhito Harada $^{1}$, Takeshi Ohta ${ }^{2}$, Takahisa Yamada ${ }^{3}$

1 Central Pharmaceutical Research Institute, Japan Tobacco Inc., Osaka, Japan

2 Laboratory of Animal Physiology and Functional Anatomy, Graduate School of Agriculture, Kyoto University, Kitashirakawa Oiwake-cho, Sakyo-ku, Kyoto, Japan

3 Graduate School of Science and Technology, Niigata University, 8050 Igarashi 2 nochou, Nishi-ku, Niigata 950-2181, Japan

\section{Short title}

JTP-109192 improves insulin sensitivity without causing tachyphylaxis

\section{Author for correspondence}

Hironobu Tadaki

Biological/Pharmacological Research Laboratories, Central Pharmaceutical Research Institute, Japan Tobacco Inc., 1-1 Murasaki-cho, Takatsuki, Osaka 569-1125, Japan

Tel.: +81726819700

Fax: +81 726819722

E-mail: hironobu.tadaki@jt.com 


\begin{abstract}
G-protein coupled receptor 119 (GPR119) expression in pancreatic $\beta$-cells and intestinal L-cells is a potential therapeutic target for treating type 2 diabetes. A natural GPR119 agonist oleoylethanolamide is well known to enhance a glucose stimulated insulin secretion (GSIS) and glucagon like peptide-1 (GLP-1) secretion by elevating intracellular cAMP levels. In the present study, a glucose lowering effect of the GPR119 agonist, JTP-109192 leading to improvement of insulin sensitivity was examined in Zucker Fatty (ZF) rats. We investigated the in vitro effects of JTP-109192 on GSIS in the rat pancreatic $\beta$-cell line (INS1E) cells and on GLP-1 secretion in the murine enteroendocrine cell line (GLUTag) cells. We also investigated the effect of JTP-109192 on GSIS in Sprague-Dawley (SD) rats with single administration and its effect on glucose metabolism in ZF rats with repeated administration once daily for about 6 weeks. After repeated administration, the hyperinsulinemic euglycemic glucose clamp test was performed to evaluate insulin sensitivity. JTP-109192 increased intracellular cAMP levels (EC50 value: $3.6 \mathrm{nmol} / \mathrm{L}$ ) and enhanced GSIS in the INS1E cells and GLP-1 secretion in GLUTag cells. In SD rats, a single administration of JTP-109192 enhanced GSIS at high blood glucose levels. The repeated administrations in ZF rats improved glucose metabolism without lack of drug efficacy (tachyphylaxis) and increased glucose infusion rates due to improvement of insulin sensitivity.
\end{abstract}

Keywords: G-protein coupled receptor 119, Diabetes, glucose clamp, insulin sensitivity, Zucker Fatty rat. 


\section{Introduction}

According to the World Health Organization (WHO), the number of adults with diabetes world-wide in 2016 is over 400 million people, due to the changes of lifestyle such as westernization of eating habits, excessive carbohydrate intake and reduction in the amount of exercise. ${ }^{1}$ It is expected that the number of diabetic patients world-wide will increase further. Diabetes is a risk factor for macrovascular diseases, such as heart attack or stroke, or other microvascular complications such as retinopathy, peripheral neuropathy, nephropathy or diabetic foot. A variety of drugs such as sulfonylurea (SU), dipeptidyl peptidase-4 (DPP-4) inhibitor, fast acting insulin secretagogue, biguanide (BG), thiazolidinedione (TZD), sodium glucose cotransporter 2 (SGLT 2) inhibitor are on the trends of diabetes remedies. However, hypoglycemia, weight gain or dehydration has been reported for their adverse effects. Therefore, the unmet medical needs still may exist for medicine which exhibits the good efficacy and less adverse effects. On the other hand, the natural history of type 2 diabetes involves the progression of impaired glucose tolerance (IGT) subjects turn to diabetic mellitus characterized by impaired insulin secretion ${ }^{2}$ and development of insulin resistance of peripheral tissue. ${ }^{3}$ Therefore, a therapeutic strategy that addresses the enhancement of glucose stimulated insulin secretion (GSIS) and leading to improvement of insulin resistance would be a better treatment for impaired insulin secretion and insulin resistance.

The target molecule in our study, G-protein coupled receptor 119 (GPR119) have been identified as Gs-coupled protein receptor. That is mainly expressed in the pancreas and in the intestinal L cells and its activation increases the levels of intracellular cyclic adenosine monophosphate (cAMP). ${ }^{4}$ The Zucker Fatty (ZF) rats are a widely used animal model of insulin resistance and have a mutation in the leptin receptor gene $\left.\left(\operatorname{Lepr}^{f a}\right)\right)^{5}$ expressing hyperinsulinemia, hypertriglyceridemia and impaired glucose tolerance associated with obesity due to polyphagia. ${ }^{6}$ Despite a great effort of pharmaceutical companies, no GPR119 agonist 
has been entered phase 3 clinical trial. GSK1292263 failed to increase blood GLP-1 level or decrease plasma glucose level in the phase 2 clinical trial. ${ }^{7}$ Significant decrease in plasma glucose level was not observed with JNJ-38431055 treatment. ${ }^{8}$ The lack of drug efficacy after repeated administration (tachyphylaxis) may provide one probable explanation for the termination. However, recent report suggested that the GPR119 agonists promote glucagon secretion under hypoglycemic conditions and this action is abolished in GPR119 knockout mice. ${ }^{9}$ Therefore, from a new aspect, the drug discovery research on GPR119 agonist still seems to be active.

In the present study, we characterized effects of single treatment with JTP-109192, a novel small-molecule agonist of GPR119, on insulin secretion in the rat pancreatic $\beta$-cell line (INS1E) cells and GLP-1 secretion in the murine enteroendocrine cell line (GLUTag) cells. We also characterized the effect of JTP-109192 with single administration on GSIS in SD rats with various blood glucose levels using hyperglycemic clamp technique and the effect with repeated administrations in ZF rats on glucose metabolism using glucose tolerance test. At the end of the period of repeated administration, the insulin sensitivity was evaluated using hyperinsulinemic euglycemic clamp technique.

\section{Results}

\subsection{GPR119 agonist activity of JTP-109192}

In this assay, we examined the human, rat and murine GPR119 agonist activity of JTP-109192, 4-[5-(3,3-dimethyl-2-oxa-spiro[4.5] dec-8-yl)-pentyloxy]-N,N-dimethyl-benzamide (Fig. 1A) by measuring cellular cAMP levels in HEK293 cells, that stably express the GPR119 protein of each species. JTP-109192 significantly increased cAMP levels in a dose-dependent manner. The $\mathrm{EC}_{50}$ values which were determined as the concentration of JTP-109192 required to achieve $50 \%$ of the maximal oleoylethanolamide (OEA) stimulated response in human, rat and mouse 
were $3.6 \pm 0.2 \mathrm{nmol} / \mathrm{L}, 4.5 \pm 0.2 \mathrm{nmol} / \mathrm{L}$ and $5.2 \pm 0.2 \mathrm{nmol} / \mathrm{L}$, respectively (Fig. 1B-D).

\subsection{Effects of JTP-109192 on insulin secretion in INS1E cells and GLP-1 secretion in GLUTag cells.}

We examined the insulinotropic effect of JTP-109192 in INS1E cells in the presence of 11.2 or $3.3 \mathrm{mmol} / \mathrm{L}$ glucose. At $1 \mu \mathrm{mol} / \mathrm{L}, \mathrm{JTP}-109192$ exerted a 1.9-fold increase in insulin secretion as compared with DMSO alone in the presence of $11.2 \mathrm{mmol} / \mathrm{L}$ glucose $(56.9 \pm 11.7 \mathrm{ng} / \mathrm{mL}$ vs. 29.6 $\pm 8.0 \mathrm{ng} / \mathrm{mL}, P<0.05$ ), while JTP-109192 did not have any effect in the presence of $3.3 \mathrm{mmol} / \mathrm{L}$ glucose (Fig.2 A). We then examined the effect of JTP-109192 on GLP-1 secretion in GLUTag cells. GLP-1 secretion was significantly increased by JTP-109192 from $0.1 \mu \mathrm{mol} / \mathrm{L}$. At $10 \mu \mathrm{mol} / \mathrm{L}, 5.6$-fold increase by JTP-109192 was observed as compared with DMSO alone $(401.0 \pm 40.7$ ng/mL vs. $113.3 \pm 46.9$ ng/mL, $P<0.01)$ (Fig.2 B).

\subsection{Effects of JTP-109192 on insulin secretion in SD rats after single administration using the hyperglycemic clamp technique.}

After overnight fasting, cannulated SD rats (7 weeks old) were administered orally $0.5 \% \mathrm{MC}$ (vehicle) or JTP-109192 (10 mg/kg). After 30 minutes, 25\% glucose solution was infused via cannula into jugular vein. By adjusting the infusion rate of the glucose solution, the blood glucose levels in both groups were elevated and were maintained at approximately $250 \mathrm{mg} / \mathrm{dL}$ for the first 60 minutes, and at $400 \mathrm{mg} / \mathrm{dL}$ for the following 60 minutes, respectively (Fig. 3A). The plasma insulin levels in the vehicle group were increased following to the elevation of the blood glucose levels, and a biphasic insulin secretion was observed at both blood glucose levels (Fig. 3B). The plasma insulin levels in the JTP-109192 group were also increased and remained higher than the vehicle group throughout the glucose infusion period. The first and the second phase insulin secretions in the JTP-109192 group were significantly enhanced at both blood 
glucose levels as compared with the vehicle group. The first phase insulin secretion was $32.2 \pm 7.2 \mathrm{ng} / \mathrm{mL} \cdot \min \quad$ vs. $\quad 12.3 \pm 3.3 \mathrm{ng} / \mathrm{mL} \cdot \min \quad(P<0.01) \quad$ at $\quad 250 \mathrm{mg} / \mathrm{dL} \quad$ and $100.4 \pm 10.7 \mathrm{ng} / \mathrm{mL} \cdot \min$ vs. $28.9 \pm 8.5 \mathrm{ng} / \mathrm{mL} \cdot \min (P<0.01)$ at $400 \mathrm{mg} / \mathrm{dL}$. The Second phase insulin secretion $444.0 \pm 54.8 \mathrm{ng} / \mathrm{mL} \cdot \min \mathrm{vs.} 122.3 \pm 22.6 \mathrm{ng} / \mathrm{mL} \cdot \min (P<0.01)$ at $250 \mathrm{mg} / \mathrm{dL}$, and $1898.1 \pm 547.6 \mathrm{ng} / \mathrm{mL} \cdot \min$ vs. $393.4 \pm 95.3 \mathrm{ng} / \mathrm{mL} \cdot \min (P<0.01)$ at $400 \mathrm{mg} / \mathrm{dL}$ (Fig. 3C, 3D).

The plasma GLP-1 levels after hyperglycemic clamp test in both portal and peripheral vein were significantly higher in the JTP-109192 group than the vehicle group (portal: $31.9 \pm 5.4 \mathrm{ng} / \mathrm{mL}$ vs. $17.4 \pm 2.4 \mathrm{ng} / \mathrm{mL}, \quad[P<0.05] ;$ peripheral: $10.0 \pm 1.4 \mathrm{ng} / \mathrm{mL}$ vs. $8.7 \pm 1.0 \mathrm{ng} / \mathrm{mL}[P<0.01 ;$ Fig. 3E $])$.

\subsection{Effects of repeated administration of JTP-109192 in Zucker Fatty rats.}

During 6 weeks of repeated administration of JTP-109192 (10 mg/kg) or vehicle, the body weight was increased and there were no differences between both groups (Fig. 4A). The plasma glucose, plasma insulin and blood HbA1c levels were lower in JTP-109192 treated group than the vehicle group (Fig. 4B-D).

\subsection{Effects of JTP-109192 on glucose metabolism in Zucker Fatty rat after single and repeated administration in intraperitoneal glucose tolerance tests.}

The plasma glucose levels of vehicle and JTP-109192 treated groups were increased after single glucose administration (Fig. 5A). The glucose levels at the dose of $10 \mathrm{mg} / \mathrm{kg}$ JTP-109192 group were remarkably reduced after glucose administration as compared with the vehicle or JTP$1091923 \mathrm{mg} / \mathrm{kg}$ group. The plasma insulin levels and insulinogenic index in the $10 \mathrm{mg} / \mathrm{kg}$ group were also increased and were higher than the vehicle or $3 \mathrm{mg} / \mathrm{kg}$ group after glucose administration (Fig. 5B, 5C). After 6 weeks of repeated administration, the glucose and insulin 
levels in the JTP-109192 $10 \mathrm{mg} / \mathrm{kg}$ group were reduced (Fig. 6A, 6B) and insulinogenic index after glucose administration was significantly higher than the vehicle group (Fig. 6C).

\subsection{Effects of repeated administration of JTP-109192 in Zucker Fatty rat in hyperinsulinemic euglycemic clamp test.}

After 6 weeks of repeated administration, the plasma GLP-1 levels before hyperinsulinemic euglycemic clamp test in peripheral vein in the JTP-109192 $10 \mathrm{mg} / \mathrm{kg}$ group were tended to be higher than the vehicle group (3.3 $\pm 0.3 \mathrm{ng} / \mathrm{mL}$ vs. $2.6 \pm 0.7 \mathrm{ng} / \mathrm{mL}, P<0.1)$ (Fig. 7A). The glucose infusion rate in JTP-109192 group was significantly higher than the vehicle group $(7.9 \pm 2.5 \mathrm{mg} / \mathrm{kg} / \mathrm{min}$ vs. $3.3 \pm 3.5 \mathrm{mg} / \mathrm{kg} / \mathrm{min}, P<0.05)$ (Fig. 7B). With further investigation, we found that the increase in glucose infusion rate in JTP-109192 group was due to suppression of hepatic gluconeogenesis (20.4 $\pm 21.0 \%$ vs. $42.1 \pm 18.3 \%, P<0.05)$ (Fig. 7C).

\section{Discussion}

In this decade, various strategies focusing on GPCRs to treat diabetes, such as GPR40, other FFARs, GIPR, GLPR, glucagon receptor, GPR55, GPR39 and GPR21, have been reported. According to GPCRome analysis, GPR119 appears to be suitable as a drug target to stimulate insulin secretion as compared with other GPCRs. ${ }^{10}$ Recently, GPR119 agonists, GSK1292263 and PSN119-1, have been showed an increase of glucagon secretion under hypoglycemic conditions in rats. ${ }^{9}$ The enhancement of glucagon secretion was directly observed in immune glucagon-positive cells, and was disappeared in GPR119 knockout mice, which is considered to act directly on GPR119 in pancreatic $\alpha$-cells. Thus, GPR119 agonists may be able to reduce the risk of hypoglycemia in insulin treatment.

The mechanism of action of GPR119 is partly common to GLP-1 analogue and DPP-4 inhibitors. In addition, GPR119 is similar to GPR40 in terms of directly promoting glucose 
sensing insulin secretion from the pancreas. Improving dyslipidemia is one of the most distinctive features of GPR119 agonist. Overexpression of GPR119 regulates cholesterol transporter expression in the intestinal lumen and liver to reduce the lipid and inflammatory cytokine levels in apo-E deficient mice. Atherosclerotic lesion was also improved. ${ }^{11}$ Therefore, the GPR119 agonist is considered to be not only an anti-diabetic but a lipid-lowering drug. In fact, GSK1292263 had been developed as drug for dyslipidemia (NCT01218204).

GPR119 agonists are often composed of three parts as follows: a piperidine or a piperazine ring $\mathrm{N}$-substituted with a carbamate or a heteroaryl group at the right side, a phenyl group substituted with a methylsulfonyl or a heteroaryl group at the left side, and a linker part connecting the two parts. We focused on the piperidine ring on the right side of the structure (typical structure for example; MBX-2982, PSN119-2) and developed JTP-109192, which has a spirocyclic cyclohexane structure on the right side. ${ }^{12,13}$ JTP-109192 has high threedimensionality and potent GPR119 agonistic activity with no cytochrome P450 (CYP) inhibitory activity, and successed to optimize lipophilicity, solubility and agonistic activity.

In the present study, this small molecule GPR119 agonist JTP-109192 enhanced GSIS and GLP-1 secretion in vitro and in vivo. After single administration of JTP-109192 at a dose of $10 \mathrm{mg} / \mathrm{kg}$ in the ipGTT study in ZF rats, the plasma glucose levels were markedly decreased and the plasma insulin levels were elevated until 30 minutes after glucose administration. The plasma concentrations of JTP-109192 at 16 hours after administration of $10 \mathrm{mg} / \mathrm{kg}$ is thought to be sufficient to improve glucose tolerance in ZF rats. During 6 weeks of repeated administration, the plasma glucose and insulin levels were tended to be decreased in the JTP$10919210 \mathrm{mg} / \mathrm{kg}$ group as compared with the vehicle group. Furthermore, JTP-109192 significantly improved the insulin sensitivity leading to suppression of hepatic gluconeogenesis. From these results, it is expected that JTP-1019192 will emerge as a potent new antihyperglycemic agent for the treatment of type 2 diabetes by improving GSIS and insulin 
resistance, and be well tolerated on long-term administration. In the preliminary study, we evaluated some known GPR119 agonist and compared with our compound. MBX2982 and GSK1292263 showed similar features as JTP-109192 on GLP-1 secretion and insulin secretion in in vitro and glucose lowering effects in in vivo. For example, in the human GPR119 cAMP assay, the EC50 values of MBX2982 and GSK1292263 were $0.7 \mathrm{nmol} / \mathrm{L}$ and $9.0 \mathrm{nmol} / \mathrm{L}$, respectively. In the GLUTag cells, the GLP-1 secretory effect of MBX2982 was potent and effective from $0.1 \mu \mathrm{mol} / \mathrm{L}$, but was weaker than JTP-109192. In the INS1E cells, the insulinotropic effect of MBX2982 was enhanced from $0.1 \mu \mathrm{mol} / \mathrm{L}$ at $11.2 \mathrm{mmol} / \mathrm{L}$ glucose condition. In the glucose tolerance test, the glucose lowering effect of JTP-109192 was similar to MBX2982 at $30 \mathrm{mg} / \mathrm{kg}$ and was more potent compared with GSK1292263. Based on these results from known GPR119 agonists which have different chemotype from our compound, JTP-109192 has potent but same mode of action as GPR119 agonist.

The GPR119 is expressed in pancreatic $\beta$-cells and intestinal L-cells. ${ }^{4}$ The OEA, a natural GPR119 agonist, is well known to enhance GSIS and GLP-1 secretion by elevating intracellular cAMP levels. ${ }^{14}$ In our study, the hyperglycemic clamp test was performed in SD rats to investigate whether JTP-109192 can enhance GSIS at different blood glucose levels, 250 and $400 \mathrm{mg} / \mathrm{dL}$. The former condition mimics the postprandial plasma glucose levels of impaired glucose tolerant (IGT) subjects and the latter mimics those of type 2 diabetic subjects. The first and second insulin secretion enhancement by JTP-109192 was in accordance with the elevation of blood glucose levels from $250 \mathrm{mg} / \mathrm{dL}$ to $400 \mathrm{mg} / \mathrm{dL}$. On the other hand, no insulinotropic effect of JTP-109192 was observed before glucose infusion (within normal blood glucose levels). Taken together, these findings suggest that JTP-109192 enhances insulin secretion with little risk of hypoglycemia, which is often observed with SUs treatment. ${ }^{15}$ We have already reported the structure-activity relationships of GPR119 agonist and its glucose lowering effect with GSIS enhancement 0.5 hour after single administration in the ipGTT in SD rats. ${ }^{12}$ 
Meanwhile, the glucose lowering effect of repeated administration on insulin resistant animals has not been evaluated. However, such an evaluation is critical in the development of GPCRs agonist because it seems that repeated administration of GPR119 agonists leads to tachyphylaxis. ${ }^{16}$

The tachyphylaxis is reported in several GPR119 agonists such as GSK1292263 and JNJ$38431055 .{ }^{17}$ In clinical trials, GSK1292263 did not increase blood active GLP-1 secretion and failed to control blood glucose levels. ${ }^{7}$ However, in the preclinical experiment, GSK1292263 maintained its glucose lowering effect after repeated dosing. ${ }^{18}$ Therefore, it is suspected that the translational research from rat to human was not sufficient. To elucidate our hypothesis, we compared GSK1292263 and JTP-109192 in in vitro. Our preliminary results showed that the pretreatment of hGPR119 by GSK1292263 reduced cAMP induction by second treatment of GSK1292263 by 43\% as compared with the response without pretreatment. On the other hand, cAMP induction after JTP-109192 pretreatment showed only 23\% decrease (data not shown). These results are similar to the report of Hothersal et al. ${ }^{19}$ Therefore, we speculate that the different degree of desensitization of GPR119 agonism is one of the reasons of tachyphylaxis. Taking into account that repeated administration of JTP-109192 improved insulin sensitivity with increasing plasma levels of active GLP-1 in ZF rats, it is indicated that JTP-109192 may not cause tachyphylaxis for at least the 6 weeks administration.

Single administration of JTP-109192 had no effect on insulin sensitivity at any infusion insulin levels (data not shown). Accordingly, it is considered that JTP-109192 ameliorates insulin resistance secondarily to its glucose lowering effect, which is in part due to a decrease of hepatic glucose production. The mechanism underlying the decrease requires further investigation. The suppression of plasma glucagon levels by JTP-109192 treatment under normoglycemic conditions (data not shown) may provide one explanation. It is also reported that the increase of GLP-1 suppresses the expression of hepatic genes such as 
phosphoenolpyruvate carboxykinase or glucose 6-phosphatase involved in glucose production. $^{20}$

In conclusion, JTP-109192 is a highly potent GPR119 agonist that enhances GSIS in INS1E cells and enhances GLP-1 secretion in GLUTag cells in vitro. In in vivo study, a single administration of JTP-109192 improves glucose tolerance. Repeated administration of JTP109192 for 6 weeks improved glucose metabolism and improved insulin sensitivity in ZF rats without lack of drug efficacy. These results suggest that JTP-1019192 represents a new potential antihyperglycemic agent that can be used for treatment of type 2 diabetes without causing tachyphylaxis.

\section{Materials and methods}

\subsection{Animals}

Animals were treated in accordance with the National Institutes of Health Guide for the Care and Use of Laboratory Animals (NIH Publications No. 8023, revised 1978). Animal study protocols were approved by the Institutional Animal Care and Use Committee of the Central Pharmaceutical Research Institute, Japan Tobacco Inc. SD and ZF rats were purchased from Charles River Laboratories Japan, Inc. (Yokohama, Japan). Husbandry conditions were maintained as follows: temperature of $23.0 \pm 3.0^{\circ} \mathrm{C}$, humidity of $55 \pm 15 \%$, 12 hour: 12 hour light:dark cycle (lights on at 8 a.m., lights off at 8 p.m.), CRF-1 pelletized diet (Oriental Yeast Co., Ltd., Tokyo, Japan) supplied ad libitum, and UV-irradiated tap water supplied ad libitum.

\subsection{Articles and cell lines}

The proceedings of structure-activity relationships of GPR119 agonist development has been previously reported. ${ }^{12}$ The test article JTP-109192, 4-[5-(3,3-dimethyl-2-oxa-spiro[4,5] dec-8yl)-pentyloxy]-N,N-dimethyl-benzamide, was one of the candidates to be synthesized in the Central Pharmaceutical Research Institute of Japan Tobacco Inc. (Osaka, Japan). JTP-109192 
or other compounds were dissolved in dimethyl sulfoxide (DMSO) (Nacalai Tesque, Inc, Japan) and used as a vehicle in cell-based assays. Metolose ${ }^{\circledR}$ SM-1500 (methylcellulose) (Shin-Etsu Chemical Co., Ltd, Japan) in a $0.5 \%$ aqueous solution was used as a vehicle in animal studies. The rat pancreatic $\beta$-cell line INS1E was licensed from Wolheim \& Maechier Experimental Diabetology Unit, Department of Cell Physiology and Metabolism, University Medical Center (Geneva, Switzerland). The murine enteroendocrine cell line GLUTag cells was licensed from Ontario Inc. (Toronto, Canada).

\subsection{GPR119 agonist activity assay}

GPR119 agonist activity was evaluated in HEK293 cells overexpressing human and rat GPR119 using a cAMP HiRange assay kit (Cisbio, Japan). The test articles in stimulation buffer [Hanks’ Balanced Salt Solution, 20 mM HEPES, 0.1\% bovine serum albumin, 0.1 mM IBMX and 0.1 mM Ro 20-1724, (cAMP-specific phosphodiesterase type IV inhibitor)] were plated in 96-well half-area plates. The cells were plated on to the plates at 12,500 cells/well in buffer mix then incubated for 30 minutes at room temperature. Thereafter, anti-cAMP cryptate conjugate was added to the wells and incubated for 3 hours at room temperature in the dark. The cellular cAMP levels were measured using a micro plate reader. The EC 50 value of JTP-109192 was determined as the concentration of the test compound required to achieve $50 \%$ of the maximal OEA stimulated response.

\subsection{Insulin secretion from INS1E cells}

The rat pancreatic $\beta$-cell line INS1E cells was maintained in Roswell Park Memorial Institute (RPMI) medium supplemented with $5 \mathrm{mmol} / \mathrm{L}$ glucose and 4.5\% FBS and aerated in a 5\%:95\% $\mathrm{CO}_{2}$ :air mixture at $37^{\circ} \mathrm{C}$. The cells were plated into 24 -well plates at the density of $3 \times 10^{5}$ cells/well and grown for 2 days. After medium was removed by aspirating, the cells 
were washed twice with Krebs-Ringer bicarbonate (KRB) buffer containing $3.3 \mathrm{mmol} / \mathrm{L}$ glucose and then incubated for 2 hours at $37^{\circ} \mathrm{C}$. The cells were then incubated with JTP-109192 (0.001-1 $\mu \mathrm{mol} / \mathrm{L})$ for 2 hours at $37^{\circ} \mathrm{C}$. The supernatant was collected to measure the insulin concentration using a rat insulin ELISA kit (Morinaga Institute of Biological Science, Inc, Japan).

\subsection{GLP-1 secretion from GLUTag cells}

The murine enteroendocrine cell line GLUTag cells was maintained in Dulbecco's Modified Eagle's Medium (DMEM) (low glucose) supplemented with 1\% penicillin-streptomycin and $10 \%$ FBS, and aerated in a 5\%:95\% $\mathrm{CO}_{2}$ :air mixture at $37^{\circ} \mathrm{C}$. The cells were plated into $24-$ well plates at the density of $1.25 \times 10^{5}$ cells/well and grown for 3 days. After medium was removed by aspirating, the cells were washed twice with KRB buffer and incubated with JTP$109192(0.001-10 \mu \mathrm{mol} / \mathrm{L})$ for 2 hours at $37^{\circ} \mathrm{C}$. The supernatant was collected to measure the active GLP-1(7-36, 7-37) concentration using a GLP-1 ELISA kit (LINCO. Research Inc, USA).

\subsection{Intraperitoneal glucose tolerance test after single and repeated administration in}

\section{Zucker Fatty rat}

ZF rats (9 weeks old) were orally administered 0.5\% methyl-cellulose (vehicle) or JTP-109192 (3 or $10 \mathrm{mg} / \mathrm{kg}$ ) and fasted. After 16 hours, rats were intraperitoneally administered glucose ( $2 \mathrm{~g} / \mathrm{kg}$ ). The blood samples were collected from the tail vein into heparinized tubes at 0 (prior to glucose administration), 30, 60 and 120 minutes after glucose administration to measure the plasma glucose concentrations, and at 0, 7, 30, 60 and 120 minutes to measure the plasma insulin concentrations. The insulinogenic index was calculated according to the following equation: 
Insulinogenic index = the area under the curve (AUC) values of plasma insulin from base line and from 0 to 30 minutes / the AUC values of plasma glucose from base line and from 0 to 30 minutes.

\subsection{Repeated treatment in Zucker Fatty rat}

Twelve male ZF rats (9 weeks old) were selected from 30 rats as follows. Four days before the start of administration, blood samples were collected from the tail vein into heparinized tubes and inverted to mix and the hemoglobin A1c (HbA1c) levels were determined. Remaining part of each blood sample was then centrifuged at $10,000 \times g$ at $4^{\circ} \mathrm{C}$ for 5 minutes to obtain plasma sample and the plasma glucose and insulin concentrations were measured. On the day of the start of the administration, the body weights were measured. After excluding 18 rats with outlier values for these parameters from the group allocation, 12 rats were assigned to 2 groups with 6 rats in each group (JTP-109192 $10 \mathrm{mg} / \mathrm{kg}$ or vehicle group) so that no bias occurred in those parameters between the 2 groups. On day 1 and 28, ipGTT was performed. On day 40 to 42, the hyperinsulinemic euglycemic clamp test was performed.

\subsection{Operation (carotid artery and jugular vein cannulation) for glucose clamp test}

SD or ZF rats were anesthetized with isoflurane. After cervical incision, cannulas (SP 45, Natsume Seisakusho Co., Ltd., Japan) were inserted into the right jugular vein (for glucose and insulin infusion) and the left carotid artery (for blood collection), and fastened to the blood vessels by suture. These two cannulas were exteriorized through the skin at the back of the neck. The incisions were sutured and sprayed with antibiotic (kanamycin, Meiji Seika Pharma Co., Ltd., Japan). The cannulas were filled with a heparin sodium solution. After cannulation, rats were fasted overnight. 


\subsection{Hyperglycemic Clamp Test in Sprague Dawley rat}

At 30 minutes before the glucose infusion, 0.5\% methyl-cellulose (vehicle) or JTP-109192 (10 mg/kg) was administered orally to conscious, freely moving, cannulated SD (7 week old) rats. Blood was collected via the carotid artery cannula to measure the blood glucose concentrations using a compact blood glucose analyzer (Antosense III, HORIBA, Ltd., Japan) every 10 minutes from 40 minutes before starting glucose infusion. 25\% glucose solution was infused via the jugular vein cannula for one minute (equivalent to $150 \mathrm{mg} / \mathrm{kg}$ ) using a syringe pump (Econoflo Syringe Pump, Harvard Bioscience, Inc., USA). The blood glucose concentrations were monitored at two and five minutes and thereafter every five minutes up to 60 minutes after the start of glucose infusion ( 0 minutes), and were maintained at approximately $250 \mathrm{mg} / \mathrm{dL}$ by adjusting the infusion rate of the glucose solution. After blood collection at 60 minutes, the glucose solution was infused via the jugular vein cannula over one minute (equivalent to $300 \mathrm{mg} / \mathrm{kg}$ ). The blood glucose concentrations were then monitored at 62 and 65 minutes and thereafter every five minutes up to 120 minutes after the start of glucose infusion, and were maintained at approximately $400 \mathrm{mg} / \mathrm{dL}$ by adjusting the infusion rate of the glucose solution. Blood samples were collected into a heparinized tube to measure the plasma insulin concentrations at 40, 30, 20, and 10 minutes before the glucose infusion, at the start of glucose infusion, and at 2, 5, 10, 20, 30, 40, 50, 60, 62, 65, 70, 80, 90, 100, 110, and 120 minutes after the start of glucose infusion. The blood was centrifuged $\left(4^{\circ} \mathrm{C}, 10,000 \times g, 5\right.$ minutes $)$ to obtain plasma. The plasma was stored at $-20^{\circ} \mathrm{C}$ until measurement of insulin concentrations. The first phase insulin secretion was calculated from the area under the curve (AUC) of plasma insulin concentrations monitored for first five minutes of glucose infusion at each blood glucose level. The second phase insulin secretion was calculated from the AUC of plasma insulin concentrations monitored for remaining 55 minutes of glucose infusion at each blood glucose level. 


\subsection{Hyperinsulinemic-Euglycemic Clamp Test in Zucker Fatty rat}

A bolus dose of insulin (3.2 U/kg) was injected via the jugular vein cannula, followed by continuous infusion of insulin solution at the rates of $15 \mathrm{mU} / \mathrm{kg} / \mathrm{min}$ using a syringe pump. Thereafter, a single drop of blood was collected via the carotid artery cannula every 5 minutes to monitor the blood glucose concentrations to adjust the infusion rate of the $25 \%$ glucose solution via the jugular vein cannula using a compact blood glucose analyzer (Medisafe Mini, Terumo Corporation, Japan). The steady-state was defined as the condition in which the blood glucose level was maintained at $110 \pm 10 \mathrm{mg} / \mathrm{dL}$ without any alteration in glucose infusion rate for 10 minutes ( 3 consecutive glucose monitoring points). At the next 3 points of the steadystate, blood samples were collected into heparinized tubes to determine the plasma insulin concentrations during the clamp period. The blood samples during the clamp periods were immediately centrifuged to obtain plasma samples. The plasma samples were stored at $-20^{\circ} \mathrm{C}$ until measurement of plasma insulin concentrations. The glucose infusion rate was calculated in accordance with the following equation:

Glucose infusion rate $(\mathrm{mg} / \mathrm{kg} / \mathrm{min})=$ Infusion rate of $25 \%$ glucose solution $(\mathrm{mL} / \mathrm{hr})$ during the clamp period $\times 250(\mathrm{mg} / \mathrm{mL}) / 60 /$ body weight $(\mathrm{kg})$

\subsection{Hyperinsulinemic-Euglycemic Clamp Test in Zucker Fatty rat (using $\left[3-{ }^{3} \mathbf{H}\right]$ glucose to determine hepatic glucose production)}

A bolus dose of $\left[3-{ }^{3} \mathrm{H}\right]$ glucose solution $(740 \mathrm{kBq} / \mathrm{rat})$ was injected via the jugular vein cannula, followed by continuous infusion at the rate of $7.4 \mathrm{kBq} / \mathrm{min}$. At 110, 115 and 120 minutes after the start of $\left[3-{ }^{3} \mathrm{H}\right]$ glucose infusion, a single drop of blood was collected via the carotid artery cannula to measure the blood glucose concentrations using a compact blood glucose analyzer (Medisafe Mini, Terumo Corporation, Japan). Blood samples were also collected into 
heparinized tubes via the carotid artery cannula to determine the plasma insulin concentrations and radioactivity of the $\left[3-{ }^{3} \mathrm{H}\right]$ glucose during the basal period. Immediately after the last blood sampling, a bolus dose of insulin (3.2 U/kg) was injected via the jugular vein cannula, followed by continuous infusion of $\left[3-{ }^{3} \mathrm{H}\right]$ glucose and insulin solution at the rates of $7.4 \mathrm{kBq} / \mathrm{min}$ and $15 \mathrm{mU} / \mathrm{kg} / \mathrm{min}$, respectively. Thereafter, a single drop of blood was collected via the carotid artery cannula every 5 minutes to monitor the blood glucose concentrations to adjust the infusion rate of the $25 \%$ glucose solution via the jugular vein cannula. The steady-state was defined as above. The next 3 points of the steady-state, blood samples were collected into heparinized tubes to determine the plasma insulin concentrations and radioactivity of the [3${ }^{3} \mathrm{H}$ ] glucose during the clamp period. The plasma samples were stored at $-20^{\circ} \mathrm{C}$ until measurement of the plasma insulin concentrations and radioactivity of the $\left[3-{ }^{3} \mathrm{H}\right]$ glucose.

\subsection{Measurement of the radioactivity of $\left[3-{ }^{3} \mathrm{H}\right]$ glucose and calculation of hepatic gluconeogenesis}

Exactly $200 \mu \mathrm{L}$ of $0.3 \mathrm{~mol} / \mathrm{L}$ zinc sulfate solution and $180 \mu \mathrm{L}$ of $0.3 \mathrm{~mol} / \mathrm{L}$ barium hydroxide solution were added to $20 \mu \mathrm{L}$ of plasma and thoroughly mixed. The mixture was centrifuged $\left(10,000 \times g\right.$, for 5 minutes, $\left.15^{\circ} \mathrm{C}\right)$ and $200 \mu \mathrm{L}$ of the $360 \mu \mathrm{L}$ of the supernatants were transferred to other tubes and evaporated to dryness for removing water including ${ }^{3} \mathrm{H}_{2} \mathrm{O}$ by heating to $100^{\circ} \mathrm{C}$ under a nitrogen gas flow. The residue was rehydrated with $300 \mu \mathrm{L}$ of purified water and thoroughly mixed with $3 \mathrm{~mL}$ of liquid scintillation cocktail (Clear-sol I, Nacalai Tesque, Inc., Japan) to measure the radioactivity of the $\left[3-{ }^{3} \mathrm{H}\right]$ glucose using a liquid scintillation counter (TRI-CARB 2500TR, PACKARD, USA).

The suppression of hepatic gluconeogenesis was calculated in accordance with the following equation:

$\mathrm{Rd}(\mathrm{mg} / \mathrm{kg} / \mathrm{min})=\mathrm{Ra}$ (Rate of glucose appearance) $=$ infusion rate of $\left[3-{ }^{3} \mathrm{H}\right]$ glucose 
(dpm/min)/specific activity of [3- $\left.{ }^{3} \mathrm{H}\right]$ glucose $(\mathrm{dpm} / \mathrm{mg}) /$ body weight $(\mathrm{kg})$

Specific activity of $\left[3-{ }^{3} \mathrm{H}\right]$ glucose $(\mathrm{dpm} / \mathrm{mg})=$ radioactivity concentration of $\left[3-{ }^{3} \mathrm{H}\right]$ glucose $(\mathrm{dpm} / \mathrm{mL}) /$ plasma glucose level $(\mathrm{mg} / \mathrm{dL}) \times 100$

Hepatic gluconeogenesis $(\mathrm{mg} / \mathrm{kg} / \mathrm{min})=\mathrm{Ra}(\mathrm{mg} / \mathrm{kg} / \mathrm{min})-$ glucose infusion rate $(\mathrm{mg} / \mathrm{kg} / \mathrm{min})$ Suppression of hepatic gluconeogenesis $(\%)=100$ - hepatic gluconeogenesis $(\mathrm{mg} / \mathrm{kg} / \mathrm{min}) /$ Basal hepatic gluconeogenesis $(\mathrm{mg} / \mathrm{kg} / \mathrm{min}) \times 100$

\subsection{Biological parameters}

Food intake, body weight, and blood biochemical parameters (HbA1c, plasma glucose and insulin) were evaluated every week. Blood samples were collected from the tail veins of rats. Glucose concentrations were measured using a commercial kit (Roche Diagnostics, Switzerland) and an automatic analyzer (Hitachi, Japan). Insulin concentrations were measured using an ELISA kit. Total hemoglobin and total HbA1c concentrations were determined using commercial kits and an automatic analyzer.

\subsection{Statistical analyses}

The significance tests were performed using the following procedures: for comparisons between 2 groups, homogeneity of variance was tested with an F-test; subsequently, the Student's $t$-test or Aspin-Welch's $t$-test was performed for homoscedastic data or heteroscedastic data, respectively. For comparisons between 3 or more groups, homogeneity of variance was tested with the Bartlett's test; subsequently, the Dunnett's test or Steel test was performed for homoscedastic data or heteroscedastic data, respectively. A 2-tailed significance level of 5\% was used. SAS System version 8.2 and SAS Preclinical Package version 5.0 (SAS Institute Japan Inc., Tokyo, Japan) were used for all statistical analysis. 


\section{Acknowledgments}

The authors express gratitude to Mr. Masao Yamanaka and Dr. Yu Motohashi who are employees of Biological/Pharmacological Research Laboratories, Central Pharmaceutical Research Institute, Japan Tobacco Inc., for conducting experiments. This research did not receive any specific grant from funding agencies in the public, commercial, or not-for-profit sectors.

\section{Disclosure}

The authors declare that there are no conflicts of interest. 


\section{References}

1. Organization

WH.

Global report

on

diabetes.

2016.

http://apps.who.int/iris/bitstream/handle/10665/204871/9789241565257_eng.pdf.

2. Fukushima M, Suzuki H, Seino Y. Insulin secretion capacity in the development from normal glucose tolerance to type 2 diabetes. Diabetes research and clinical practice. 2004;66 Suppl 1:S37-43.

3. Phillips LS, Ratner RE, Buse JB, Kahn SE. We can change the natural history of type 2 diabetes. Diabetes care. 2014;37(10):2668-2676.

4. Chu ZL, Carroll C, Alfonso J, et al. A role for intestinal endocrine cell-expressed g proteincoupled receptor 119 in glycemic control by enhancing glucagon-like Peptide-1 and glucosedependent insulinotropic Peptide release. Endocrinology. 2008;149(5):2038-2047.

5. Phillips MS, Liu Q, Hammond HA, et al. Leptin receptor missense mutation in the fatty Zucker rat. Nature genetics. 1996;13(1):18-19.

6. Okuno A, Tamemoto H, Tobe K, et al. Troglitazone increases the number of small adipocytes without the change of white adipose tissue mass in obese Zucker rats. The Journal of clinical investigation. 1998;101(6):1354-1361.

7. Nunez DJ, Bush MA, Collins DA, et al. Gut hormone pharmacology of a novel GPR119 agonist (GSK1292263), metformin, and sitagliptin in type 2 diabetes mellitus: results from two randomized studies. PloS one. 2014;9(4):e92494. 
8. Katz LB, Gambale JJ, Rothenberg PL, et al. Effects of JNJ-38431055, a novel GPR119 receptor agonist, in randomized, double-blind, placebo-controlled studies in subjects with type 2 diabetes. Diabetes, obesity \& metabolism. 2012;14(8):709-716.

9. Li NX, Brown S, Kowalski T, et al. GPR119 Agonism Increases Glucagon Secretion During Insulin-Induced Hypoglycemia. Diabetes. 2018;67(7):1401-1413.

10. Amisten S, Salehi A, Rorsman P, Jones PM, Persaud SJ. An atlas and functional analysis of G-protein coupled receptors in human islets of Langerhans. Pharmacology \& therapeutics. 2013;139(3):359-391.

11. Hu YW, Yang JY, Ma X, et al. A lincRNA-DYNLRB2-2/GPR119/GLP-1R/ABCA1dependent signal transduction pathway is essential for the regulation of cholesterol homeostasis. Journal of lipid research. 2014;55(4):681-697.

12. Harada K, Mizukami J, Kadowaki S, et al. Design and synthesis of novel and potent GPR119 agonists with a spirocyclic structure. Bioorganic \& medicinal chemistry letters. 2018;28(7):1228-1233.

13. Harada K, Mizukami J, Watanabe T, et al. Lead generation and optimization of novel GPR119 agonists with a spirocyclic cyclohexane structure. Bioorganic \& medicinal chemistry letters. 2019;29(3):373-379.

14. Overton HA, Babbs AJ, Doel SM, et al. Deorphanization of a G protein-coupled receptor for oleoylethanolamide and its use in the discovery of small-molecule hypophagic 
agents. Cell metabolism. 2006;3(3):167-175.

15. Sola D, Rossi L, Schianca GP, et al. Sulfonylureas and their use in clinical practice. Archives of medical science : AMS. 2015;11(4):840-848.

16. Kang SU. GPR119 agonists: a promising approach for T2DM treatment? A SWOT analysis of GPR119. Drug discovery today. 2013;18(23-24):1309-1315.

17. Han T, Lee BM, Park YH, et al. YH18968, a Novel 1,2,4-Triazolone G-Protein Coupled Receptor 119 Agonist for the Treatment of Type 2 Diabetes Mellitus. Biomolecules \& therapeutics. 2018;26(2):201-209.

18. Shah U, Kowalski TJ. GPR119 agonists for the potential treatment of type 2 diabetes and related metabolic disorders. Vitamins and hormones. 2010;84:415-448.

19. Hothersall JD, Bussey CE, Brown AJ, Scott JS, Dale I, Rawlins P. Sustained washresistant receptor activation responses of GPR119 agonists. European journal of pharmacology. 2015;762:430-442.

20. Yang M, Wang J, Wu S, et al. Duodenal GLP-1 signaling regulates hepatic glucose production through a PKC-delta-dependent neurocircuitry. Cell death \& disease. 2017;8(2):e2609. 


\section{Figure Legends}

Figure 1
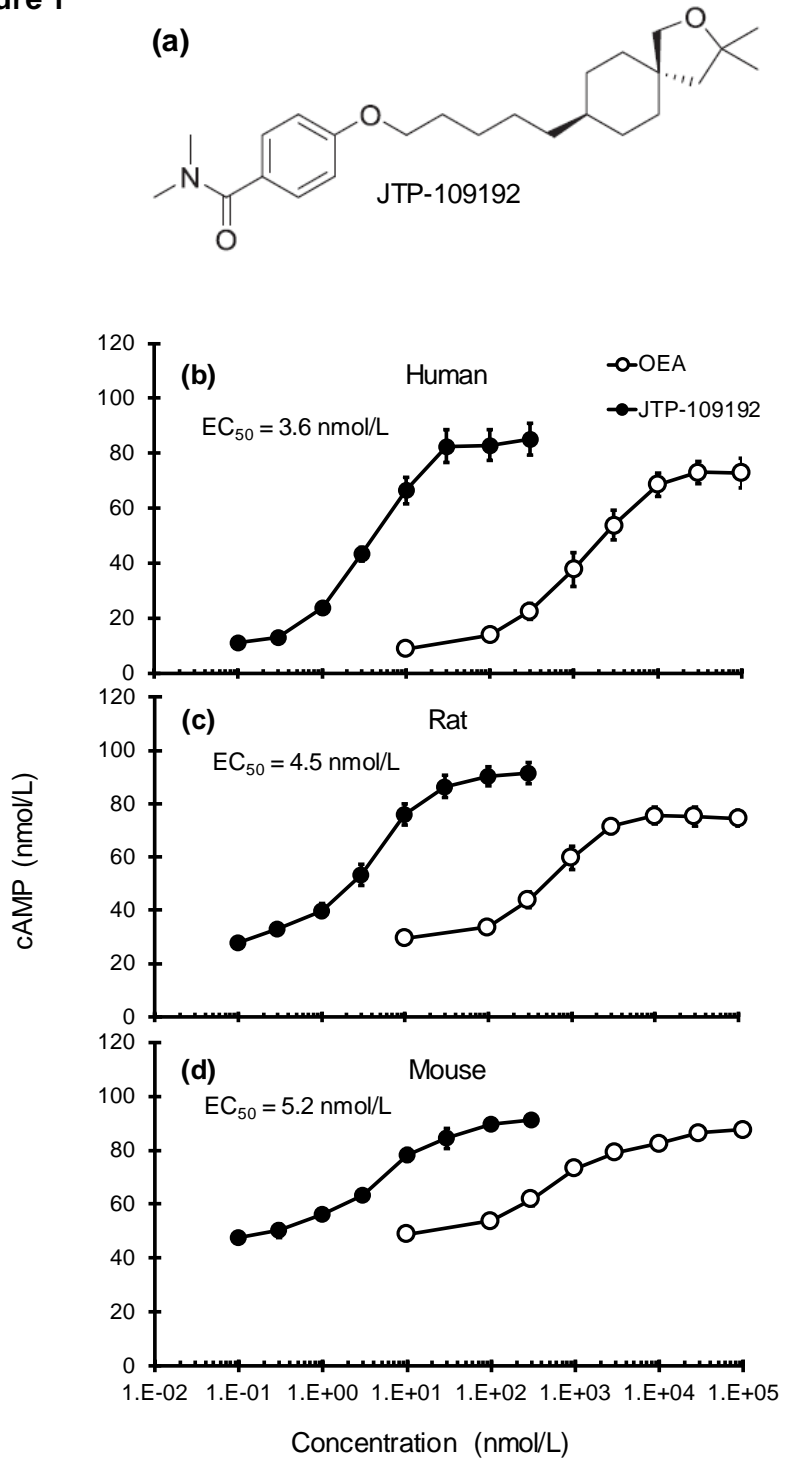

Figure 1. The GPR119 agonist activity of JTP-109192 in HEK293 cells expressing stable human, rat and mouse GPR119 protein. Oleoylethanolamide (OEA), a natural GPR119 agonist, was used as a reference compound. The $\mathrm{EC}_{50}$ value was determined as the concentration of the test compound required to achieve $50 \%$ of the maximal OEA stimulated response.

(A) Chemical structure of JTP-109192. The concentration-response curves of JTP-109192 on intracellular cAMP in HEK293 cells expressing human (B), rat (C) and mouse (D) GPR119 protein. Data are presented as the mean \pm standard error of the mean of the $\mathrm{EC}_{50}$ values in four independent trials; $\mathrm{n}=3$. 


\section{Figure 2}
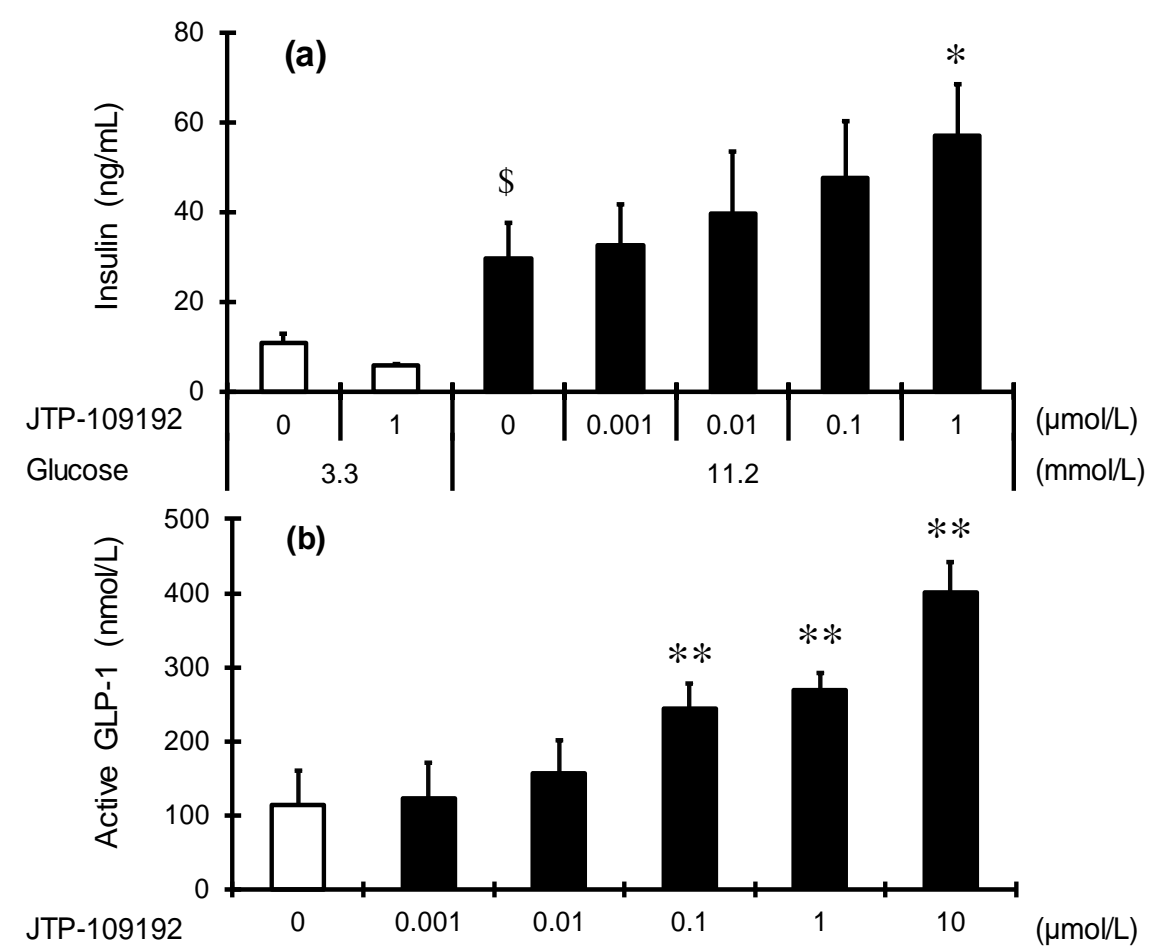

Figure 2. The effects of JTP-109192 on insulin secretion in INS1E cells and GLP-1 secretion in GLUTag cells.

(A) shows the concentration-response curves of JTP-109192 on insulin secretion in INS1E cells at 3.3 and $11.2 \mathrm{mmol} / \mathrm{L}$ glucose condition. Data are presented as the mean \pm standard deviation; $\mathrm{n}=4 .{ }^{\$} \mathrm{P}<0.05$ vehicle at $3.3 \mathrm{mmol} / \mathrm{L}$ vs. vehicle at $11.2 \mathrm{mmol} / \mathrm{L}$ group (Student's $t$-test); ${ }^{*} P<0.05$ vs. vehicle group (Dunnett's test). (B) shows the concentration-response curves of JTP-109192 on GLP-1 secretion in GLUTag cells. Data are presented as the mean \pm standard deviation; $\mathrm{n}=4 .{ }^{* *} \mathrm{P}<0.01$ vs. vehicle group (Dunnett's test). 
Figure 3
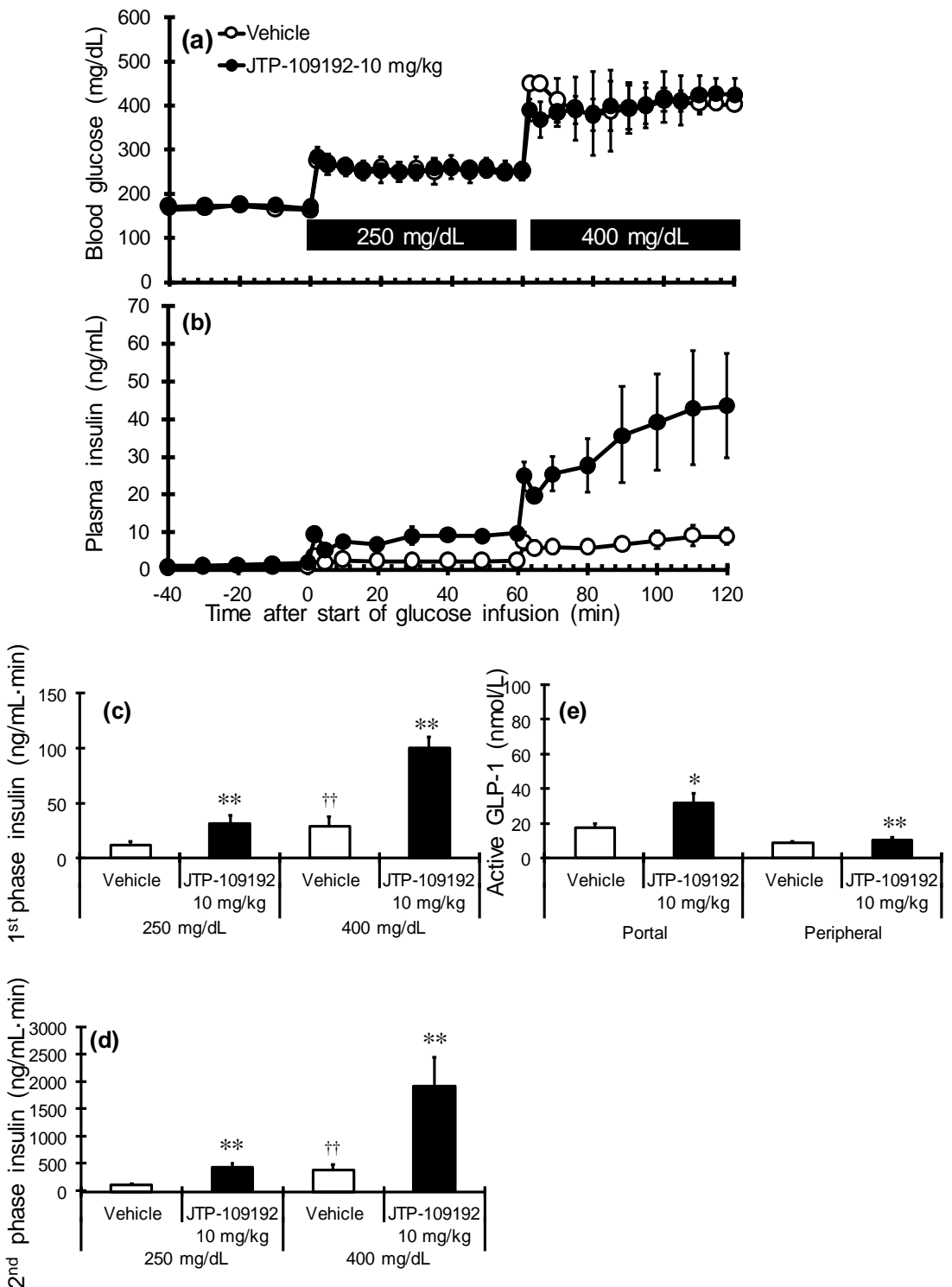

Figure 3. The effects of JTP-109192 on insulin secretion in SD rats after single administration using hyperglycemic clamp technique.

(A) shows the blood glucose levels at 250 and $400 \mathrm{mg} / \mathrm{dL}$ by adjusting infusion rate of the glucose solution. (B) shows the plasma insulin levels during the hyperinsulinemic euglycemic clamp test. (C) shows first phase insulin secretion. (D) shows second phase insulin secretion. (E) shows plasma GLP-1 levels in the portal and peripheral veins. Data are presented as the mean \pm standard deviation; $\mathrm{n}=5-6 .{ }^{\dagger+} \mathrm{P}<0.01$ vehicle group at $400 \mathrm{mg} / \mathrm{dL}$ vs. $250 \mathrm{mg} / \mathrm{dL}$ (Aspin-Welch's $t$-test); ${ }^{*} P<0.05,{ }^{* *} P<0.01$ vs. vehicle group (Student's $t$-test). 

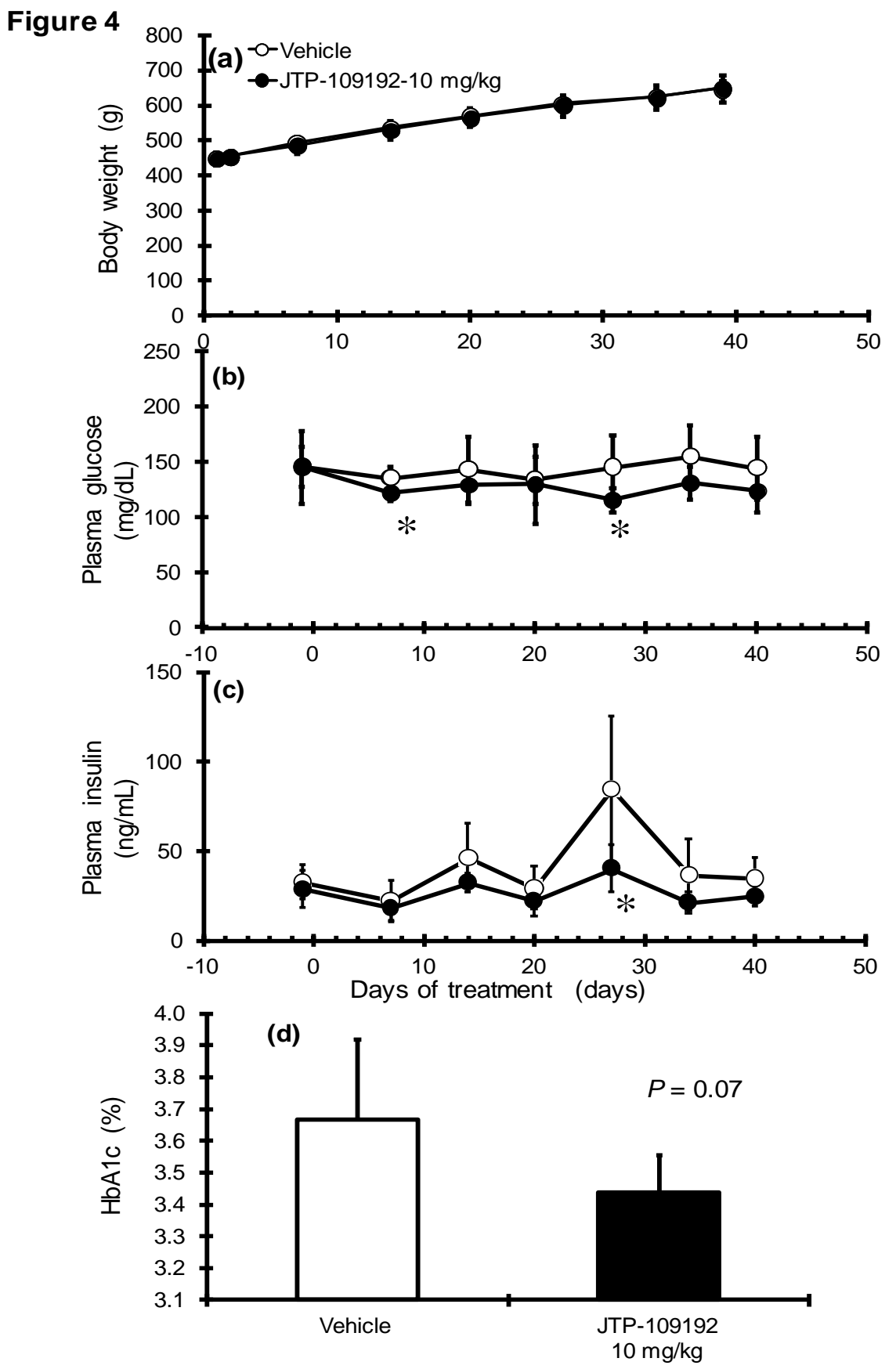

Figure 4. The effect of JTP-109192 on body weight, food intake, plasma glucose and plasma insulin levels in ZF rats.

(A) shows the body weight during the repeated administration. No change were observed between JTP-109192 10 mg/kg and vehicle groups. (B) shows the plasma glucose levels during the repeated administration. (C) shows the plasma insulin levels during the repeated administration. (D) shows the blood HbA1c levels on day 40. Data are expressed as the mean \pm standard deviation; $\mathrm{n}=6 .{ }^{*} \mathrm{P}<0.05$ vs. vehicle group (Student's $t$-test). 
Figure 5
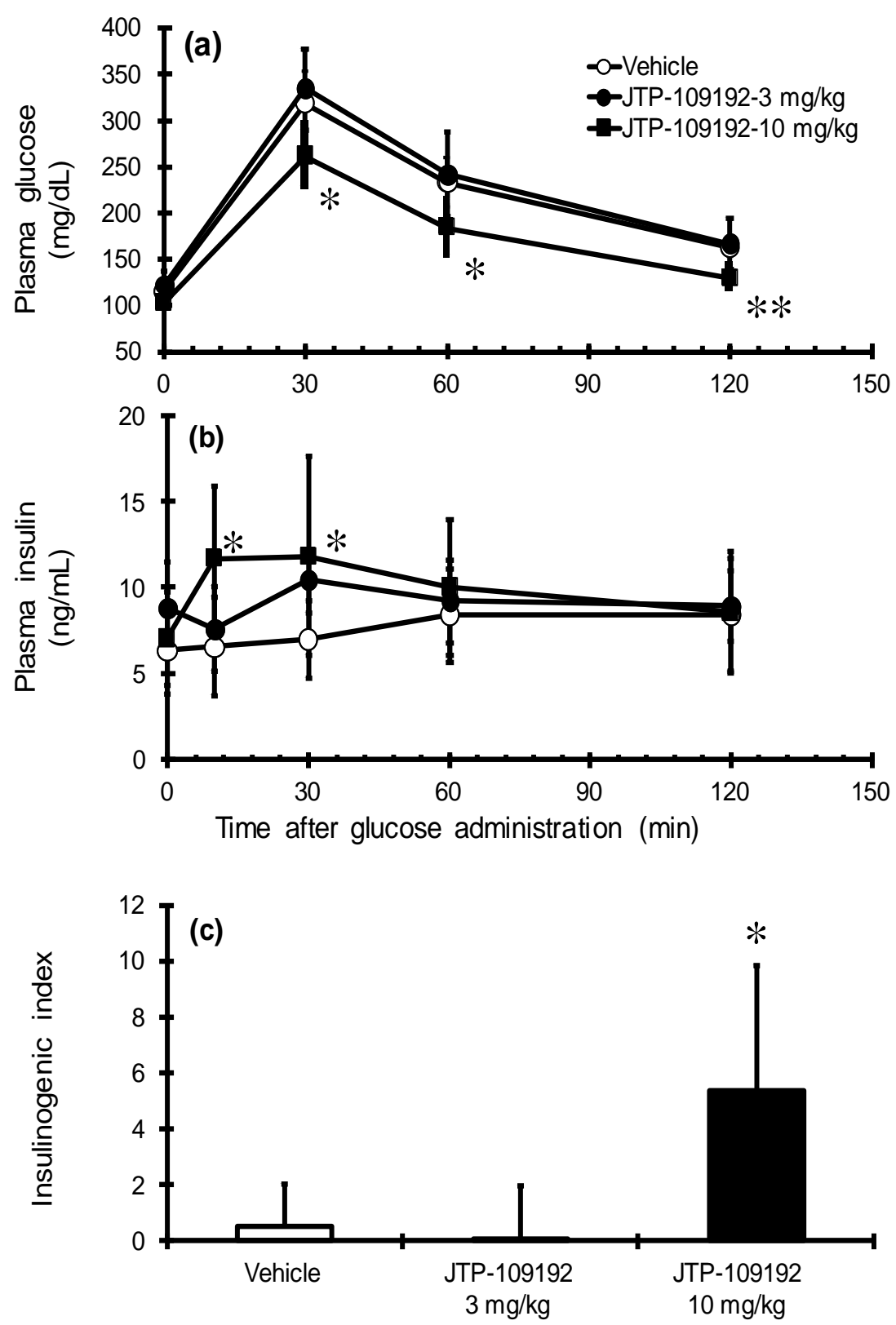

Figure 5. The effects of JTP-109192 on intraperitoneal glucose tolerance test after single administration in ZF rats.

(A) shows the plasma glucose levels during the glucose tolerance test. (B) shows the plasma insulin levels during the glucose tolerance test. (C) shows the insulinogenic index during the glucose tolerance test. Data are expressed as the mean \pm standard deviation; $n=6$. ${ }^{*} P<0.05$, ${ }^{* *} P<0.01$ vs. vehicle group (Dunnett's test). 
Figure 6
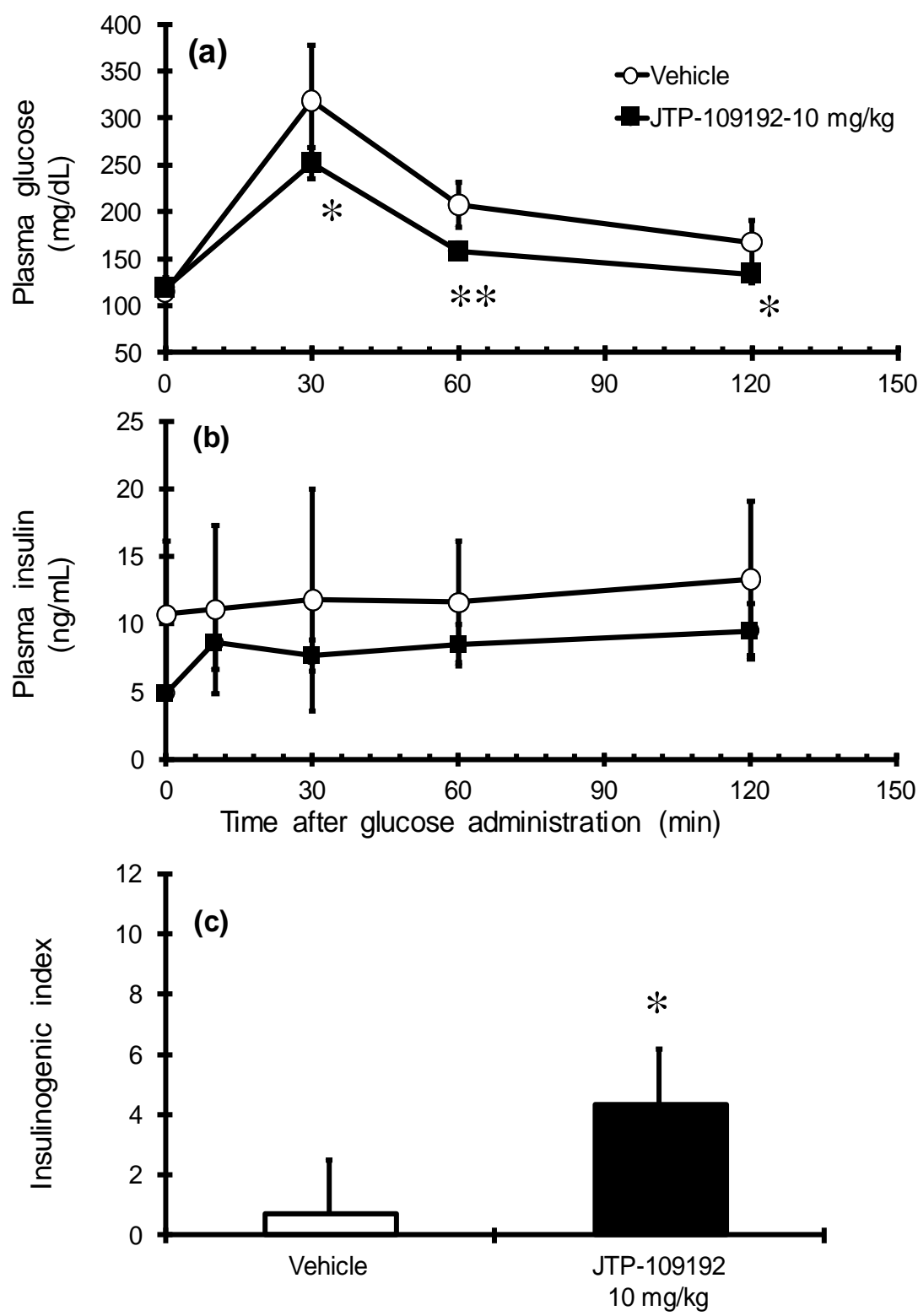

Figure 6. The effects of JTP-109192 on intraperitoneal glucose tolerance test after repeated administration in ZF rats.

(A) shows the plasma glucose levels during the glucose tolerance test (B) shows the plasma insulin levels during the glucose tolerance test. (C) shows the insulinogenic index during the glucose tolerance test. Data are expressed as the mean \pm standard deviation; $n=6$. ${ }^{*} P<0.05$, ${ }^{* *} P<0.01$ vs. vehicle group (Student's $t$-test). 
Figure 7
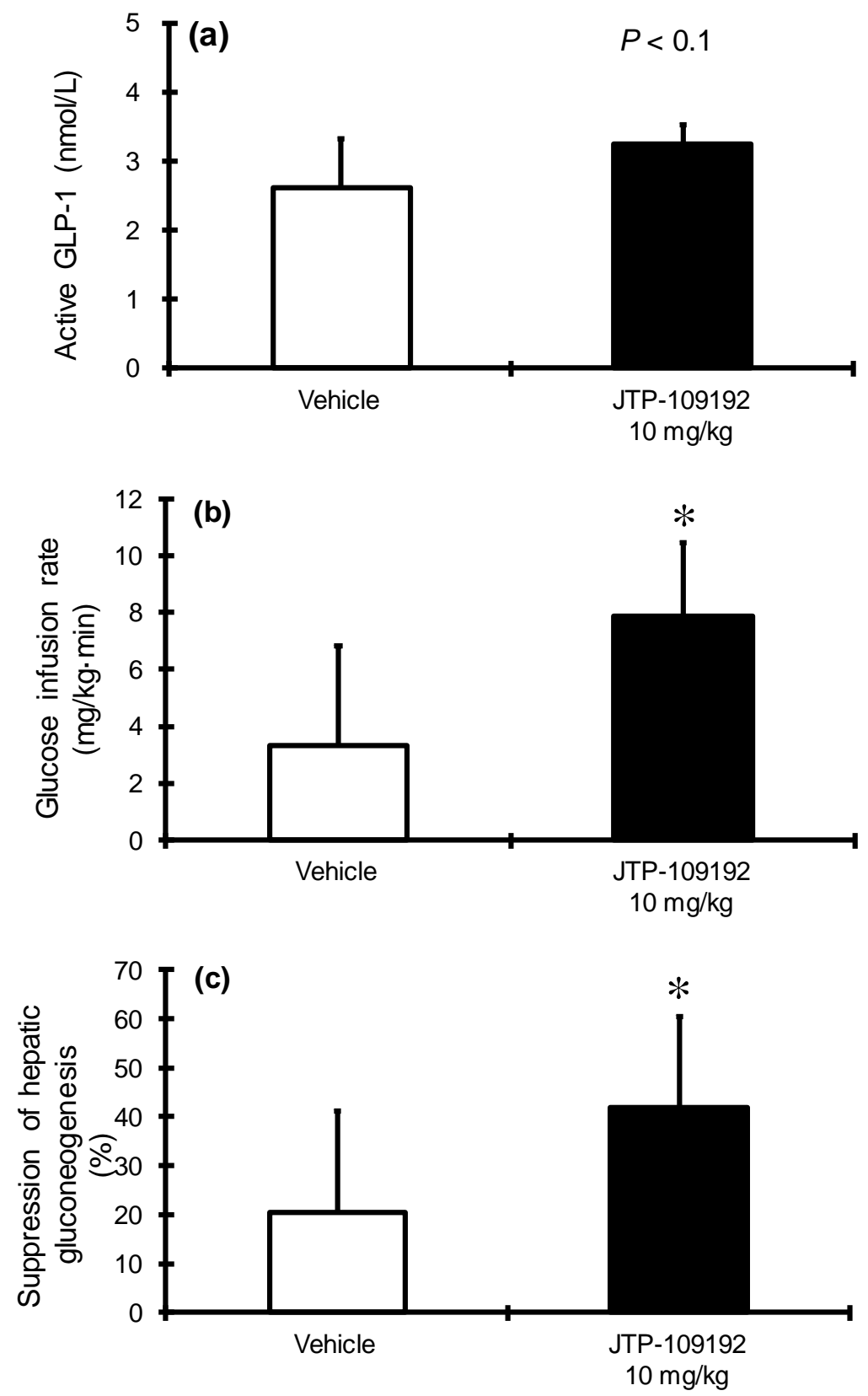

Figure 7. The effects of JTP-109192 on insulin sensitivity after repeated administration in ZF rats.

(A) shows the plasma GLP-1 levels in peripheral vein. (B) shows the glucose infusion rates during the hyperinsulinemic euglycemic clamp test. Data are expressed as the mean \pm standard deviation; $n=6$ rats. (C) shows the suppression of hepatic gluconeogenesis during the hyperinsulinemic euglycemic clamp test. Data are expressed as the mean \pm standard deviation; $\mathrm{n}=8 .{ }^{*} \mathrm{P}<0.05$ vs. vehicle group (Student's $t$-test). 